\title{
Which patients do GPs refer to which professional
}

\author{
K. O'Neill-Byrne and Sally M. Browning
}

\begin{abstract}
Referral rates to three groups of mental health profestonals working in primary care were compared. All patients referred over an 18-month period af two health centres in an outer London borough were assessed by case-note review and data were collected on 181 consecuttve referrals. In general, younger, more socially-stable patients were referred to the paychologist and older patients were seen by the CPN. The psychologist saw most new patients; patients previously seen by a psychicitist were most likely to be referred again to a psychiatrist. Patients requesting referral to a mental health professional were most likely to be referred to the poychologist. Patients with a dlagnosis of psychosis were seen mainly by the psychiatist and the CPN; the psychiatrist saw most patients with a personality disorder. A high proportion of patients were seen for assessment only. In general, all interventions were brief. There was evidence of selection by GPs in the referral of patients to each mental heaith proteseional.
\end{abstract}

Several workers have published descriptive and evaluative studies of the work of the psychiatrist in a primary care setting. Various services are described, from Nottingham where most patients seen were already known to the hospital service (Tyrer, 1984) to Bristol where a higher proportion of new patients was seen (Browning et al, 1987). Several studies have demonstrated a higher attendance at the general practice clinic when compared to a hospital out-patient clinic (Tyrer, 1984; Brown et al, 1988; Strathdee et al, 1990).

The provision of mental health care in this setting has also involved clinical psychologists, community psychiatric nurses, social workers and counsellors (Wilkinson, 1988).

\section{Study}

The present study compares referrals to and activities of psychologists, nurse and psychiatrists in primary care settings.

Practice $A$ is a group practice (six partners) situated in an area of high unemployment and social deprivation on the outskirts of London, providing a service for 12000 patients. A psychiatrist works in the practice for one weekly session; two psychologists provide a session each. and the community psychiatric nurse is avallable daily in the practice. A psychiatric liaison meeting takes place fortnightly for discussion and consultation.

Six partners and two GP trainees work in practice $B$, which is sited in a middle-class suburb with relatively low unemployment and social disruption. Twelve thousand patients are served by this practice. A CPN and psychiatrist provide one session per week in the surgery and a clinical psychologist attends twice weekly. No formal liaison meeting takes place.

All professionals offer a rapid assessment service and waiting times for appointments are similar for all disciplines. All referrals of patients over 65 go directly to the psychogeriatric team at the local hospital. Neither practice has an attached social worker.

All GP referrals to an "in-house" mental health professional in the two surgeries over a period of 18 months were studied. The following information was gathered from the case-notes of each patient referred: demographic data, previous psychiatric history, reason for referral and outcome of referral. The categories under "reason for referral" were those used by Kaeser \& Cooper (1971). An additional category had to be included to accommodate referrals to the CPN: this was "referred for social support". The outcome of referral was assessed by collecting information on diagnosis, length of intervention, number of appointments and type of intervention. Information was also collected on non-attenders.

The data obtained were compared across the three disciplines to ascertain whether any specific factors determined the professional to whom referral was made.

\section{Findings}

Of 181 referrals, over half (103) were referred to the clinical psychologists, 50 to the psychiatrists and 28 to the CPNs.

The psychologists saw a proportionately larger group of young adults than the psychiatrist or the 
CPNs: patients under the age of 35 constituted $57 \%$ of the psychologists' work. This difference was statistically significant $\left(\chi^{2}=23.96\right.$, d.f. $=8$, $P<0.01)$. At the other end of the age scale, patients over the age of 55 made up one-third of the CPN's work. All three disciplines saw comparable proportions of married patients, but divorced/separated patients constituted only $9 \%$ of the psychologists' work, compared with $20 \%$ of the psychiatrists' and $36 \%$ of the CPNs' $\left(\chi^{2}=20.8\right.$, d.f. $=10, P<0.05$ ).

Another significant difference was in the area of employment status: here half of the psychologists' referred patients were in full-time employment and only $8 \%$ were unemployed. This contrasted markedly with referrals to the other two disciplines where $28 \%$ of psychiatrists' and $21 \%$ of CPN's referrals were unemployed $\left(\chi^{2}=23.74\right.$, d.f. $\left.=8, P<0.01\right)$.
More than half the patients referred (108) had no previous psychiatric history. "New" patients constituted a higher proportion of referrals to psychologists $(70 \%)$ than to CPNs $(53 \%)$ and to psychiatrists (42\%). Patients who had been seen in the past by a psychiatrist constituted half of the referrals to the psychiatrists and nearly $40 \%$ of the CPN but under $10 \%$ of the psychologists' $\left(\chi^{2}=39.59\right.$, d.f. $\left.=6, P<0.001\right)$

The reason for referral, clinical diagnosis and treatment pattern are summarised in Table 1. The vast majority of patients were referred either for specialist opinion and advice or because of a perceived need for a special form of treatment. such as psychotherapy, anxiety management or lithium therapy. Surprisingly few patients were referred because of failure of GP treatment: a trend towards prompt referral was noted in both of the surgeries, with institution of treatment

Table 1. Characteristics of referrals to professionals

\begin{tabular}{|c|c|c|c|c|c|c|c|c|}
\hline \multirow[b]{2}{*}{ Recison for referral" } & \multicolumn{2}{|c|}{$\begin{array}{l}\text { Psychiatrist } \\
(n=50)\end{array}$} & \multicolumn{2}{|c|}{$\begin{array}{l}\text { Psychologist } \\
(n=103)\end{array}$} & \multicolumn{2}{|c|}{$\begin{array}{l}\text { CPN } \\
(n=28)\end{array}$} & \multicolumn{2}{|c|}{$\begin{array}{l}\text { Total } \\
(n=181)\end{array}$} \\
\hline & & & & & & & & \\
\hline Behoviour disturbance/severe soclal difflculties & 6 & (12\%) & 1 & (1\%) & 2 & (7\%) & 9 & $(5 \%)$ \\
\hline Suicidal risk & 4 & $(8 \%)$ & 0 & - & 3 & (11\%) & 7 & (4\%) \\
\hline Failure to respond to GP treatment & 6 & $(12 \%)$ & 2 & $(2 \%)$ & 0 & - & 8 & (4\%) \\
\hline Need for special form of treatment & 12 & $(24 \%)$ & 49 & $(48 \%)$ & 14 & $(50 \%)$ & 74 & $(41 \%)$ \\
\hline Specialist opinion/advice sought & 25 & $(50 \%)$ & 50 & $(49 \%)$ & 7 & $(25 \%)$ & 82 & (45\%) \\
\hline Patient request & 7 & $(14 \%)$ & 27 & $(26 \%)$ & 4 & $(14 \%)$ & 38 & (21\%) \\
\hline "Support" & 0 & - & 0 & - & 4 & (14\%) & 4 & $(2 \%)$ \\
\hline \multicolumn{9}{|l|}{ Clinical dilagnosis": } \\
\hline Psychosis & 3 & $(6 \%)$ & 1 & $(1 \%)$ & 4 & $(14 \%)$ & 8 & $(4 \%)$ \\
\hline Depression & 17 & $(34 \%)$ & 6 & $(6 \%)$ & 4 & $(14 \%)$ & 27 & (15\%) \\
\hline Anxiety/panic disorders & 4 & $(8 \%)$ & 21 & $(20 \%)$ & 9 & $(32 \%)$ & 34 & (19\%) \\
\hline Personallty disorder & 11 & $(22 \%)$ & 4 & $(4 \%)$ & 2 & $(7 \%)$ & 17 & $(9 \%)$ \\
\hline \multirow{2}{*}{\multicolumn{9}{|c|}{ Treatment" }} \\
\hline & & & & & & & & \\
\hline Physical & 18 & $(36 \%)$ & 1 & $(1 \%)$ & 4 & $(14 \%)$ & 23 & (13\%) \\
\hline $\begin{array}{l}\text { Counselling } \\
\text { Psychotherapy }\end{array}$ & 0 & - & 17 & (17\%) & 4 & $(14 \%)$ & 21 & $(12 \%)$ \\
\hline Cognittive therapy & 11 & & 281 & & 2) & & 311 & \\
\hline Psychoanalytic psychotherapy & $0 \int_{5}$ & & 11 & & 0 & & 11 & \\
\hline $\begin{array}{l}\text { Behaviour therapy } \\
\text { Other therapy }\end{array}$ & $\left.\begin{array}{l}2 \\
2\end{array}\right]^{5}$ & $(10 \%)$ & $\begin{array}{l}8 \\
1\end{array}$ & $48(4 / \%)$ & 9 & $2(43 \%)$ & $\begin{array}{r}19 \\
4\end{array}$ & $05(36 \%)$ \\
\hline Referred on: & 6 & $(12 \%)$ & 1 & $(1 \%)$ & 1 & $(4 \%)$ & 8 & $(4 \%)$ \\
\hline Day Hospital & 4 & $(8 \%)$ & 0 & - & 1 & $(4 \%)$ & 5 & (3\%) \\
\hline Inpatient admission & 0 & - & 1 & (1\%) & 1 & $(4 \%)$ & 2 & (1\%) \\
\hline Social intervention & 0 & - & 0 & - & 3 & $(11 \%)$ & 3 & $(2 \%)$ \\
\hline Assessment: no action & 19 & $(38 \%)$ & 29 & (28\%) & 2 & $(7 \%)$ & 50 & $(28 \%)$ \\
\hline \multicolumn{9}{|l|}{ Number of Appointments } \\
\hline Non-attenders & 3 & $(6 \%)$ & 6 & $(6 \%)$ & 0 & - & 9 & $(5 \%)$ \\
\hline Assessment only & 25 & $(50 \%)$ & 30 & $(29 \%)$ & 4 & $(14 \%)$ & 59 & (33\%) \\
\hline Up to 3 & 9 & $(18 \%)$ & 17 & $(17 \%)$ & 8 & $(28 \%)$ & 34 & (19\%) \\
\hline Up to 12 & 8 & $(16 \%)$ & 38 & $(37 \%)$ & 10 & $(36 \%)$ & 56 & (31\%) \\
\hline Up to 24 & 1 & $(2 \%)$ & 5 & $(5 \%)$ & 4 & $(14 \%)$ & 10 & $(6 \%)$ \\
\hline$>24$ & 4 & $(8 \%)$ & 7 & $(7 \%)$ & 2 & $(7 \%)$ & 13 & $(7 \%)$ \\
\hline
\end{tabular}

"Total exceed 181 because in some cases 2 categories were of equal importance

"Total are less than referrals because of non-attenders ( 3 for psychiatry, 6 for psychology, 0 for CPN) 
usually awaiting the advice of the mental health professional. When the request for referral had come from the patient, referral to a psychologist was most likely to follow. The patients referred for assessment of suicide risk were seen by the psychiatrist and CPNs. Patients referred for social support were referred exclusively to the CPNs. As one would expect, the majority of patients who received physical treatment were seen by the psychiatrist or the CPN. What was of interest, however, was the proportion of patients seen by the CPN who were treated on purely psychological lines (57\%).

With respect to diagnosis, only a small number of patients had a psychotic illness. The highest proportion of these was seen by the CPN. Anxiety/panic disorders formed the largest single category of patients seen by the psychologists $(22 \%)$ and the CPN (32\%); depression the largest category seen by the psychiatrist (36\%). An unexpectedly high proportion (22\%) of patients with personality disorder was seen by the psychiatrists in this study. A large proportion (56\%) of the psychologists' referrals fell into a catch-all category; "other". This category consisted of patients without a formal diagnosis of mental illness, whose problems included relationship difficulties, lack of confidence and low selfesteem. Four of nine patients referred to the psychiatrists were simply described as having "no mental illness" and of eight patients referred to the CPNs four had social problems, mainly related to housing.

The psychiatrists referred the highest proportion of patients seen $(13 \%)$ on to another professional or agency and sent the highest proportion $(9 \%)$ to the psychiatric day hospital. Only the CPNs engaged in purely social intervention.

It is clear from the figures that the consultation/brief intervention model predominated in all three disciplines, with 105 patients being seen for fewer than three months and 93 being seen on less than three occasions.

\section{Comment}

This study is the first to compare referrals to psychiatrists, psychologists and CPNs working within primary care.

Patients referred to the CPNs were in general male, older, more likely to be divorced/separated and less likely to be in full-time employment than patients referred to psychologists or psychiatrists. CPNs and psychiatrists saw a higher proportion of patients perceived to have a risk of suicide and a lower proportion of "new" patients.

The CPNs saw all the patients referred for "social support". There have been concerns raised in the literature about the scope of clinical activities expected from CPNs (Tyrer, 1990). In this study, the main activities of CPNs comprised the provision of behavioural psychotherapy for anxlous patients, administration of depot injections and social intervention. Of the small number of psychotic patients referred, most were seen by the CPNs, implying that this traditional aspect of their role is still relevant in the eyes of GPs.

Patients referred to psychologists, on the other hand, were more likely to be under 35 and in full-time employment. It was noted that selfreferral for psychological help most often led to referral to the psychologist. It is possible that younger patients with less social disruption in their lives are more likely to seek such help directly than other patient groups. The high overall number of referrals made to the psychologists is of interest: undoubtedly the fact that the psychologists had more available clinical time than other disciplines will have had some influence, but it also may be that referral to a psychologist is seen as more acceptable to many patients by their GPs. Moreover, patients who themselves request referral may not be considered "ill" enough to warrant referral to a psychiatrist or CPN.

A history of having been seen by a psychiatrist in the past is more likely to result in a referral to a psychiatrist or a CPN than to a psychologist. This reflects earlier findings (Farmer \& Griffiths, 1992) which highlighted the influence of a psychiatric label and greater severity of symptoms.

Classified as "other" are patients who did not receive a formal diagnosis, but were the subject of psychodynamic formulations. Most went on to receive therapy (usually cognitive in type) or were seen only for assessment. While this group predominated amongst psychologist referrals, they also formed a significant proportion of the psychiatrists' $(20 \%)$ and the CPNs' $(28 \%)$ work.

The presence of the "other" category leads into the vexed question of whether primary care clinics are seeing less "ill" patients at the expense of the chronically-unwell and psychotic. Only eight of the 181 referred patients in the present study had a psychotic illness. It is important to note that patients with lifelong illnesses were often already in contact with the psychiatric services in more traditional settings such as hospital out-patient clinics. This echoes the experience in a recent review of the work of a community mental health team based in primary care (Jackson et al, 1993). The psychiatrists saw half the patients referred for assessment only, a further $18 \%$ for a brief intervention of less than 3 months.

The present study demonstrates that, where GPs have access to mental health professionals of different disciplines, they refer different patient groups to each professional, using their skills in a specialist rather than a generic way. 
A prospective study using the multi-axdal classification system proposed by Jenkins et al (1988) would help us to better understand what precisely informs this decision on the part of the GP.

\section{Acknowledgement}

This study was supported in part by a grant from the Locally Organised Research Scheme.

\section{References}

Brown, R. M. A., StrathdeE, G., Christie-Brown, J. R. W. . et al (1988) A comparison of referrals to primary-care and hospital outpatient clinics. British Joumal of Psychiatry. 163, 168-173.

BROWNING, S. M., FORD, M. F., GODDARD, C. A. et al (1987) A psychiatric clinic in general practice: a description and comparison with an outpatient clinic. Bulletin of the Royal College of Psychiatrists, 11, 114-117.

FARMER, A. E. \& GRIFFTrHS. H. (1992) Labelling and illness in primary care: comparing factors influencing general practitioners' and psychiatrists' decisions regarding referral to mental illness services. Psychological Medictne, 22, 717-723.
JACKSON, G., GATER, R., GOLDBERG, D., et al (1993) A new community mental health team based in primary care. A description of the service and its effect on service use in the first year. Brttish Journal of Psychiatry, 162, 375384.

JENKINS, R. SMEETON, N. \& SHEPHERD, M. (1988) Classiffcation of Mental Disorder in Primary Care. Psychological Medicine. Monograph Supplement 12.

KAESER, A. C. \& COOPER, B. (1971) The poychilatilc patient, the general practitioner and the outpatient clinic: an operational study and a review. Psychological Medicine. 1. 312-325.

StrathdeE, G., King, M. B., ArAYA, R, et al (1990) A standardised assessment of patients referred to primary care and hospital psychiatry clinics. Psychological Medicine, 20, 219-224.

TYRER. P. (1984) Psychiatric clinics in general practice: an extension of community care. Brttish Journal of Psychiatry, 145. 9-14.

- (1990) The role of the community psychiatric nurse. British Joumal of Hospital Medictne, 43, 439-442.

WIuKInSON, G. (1988) I don't want you to see a psychilatrist. Brttsh Medical Journal, 287, 1144-1145.

"Katrina O'Neill-Byrne and Sally M. Browning, Bexdey Hospital, Old Bexdey Lane, Bexdey, Kent DA5 2BW

"Correspondence 